\title{
Acute Hypotension after High-Intensity Interval Exercise in Metabolic Syndrome Patients
}

\author{
Authors \\ Felix Morales-Palomo ${ }^{1}$, Miguel Ramirez-Jimenez ${ }^{1}$, Juan Fernando \\ Ortega ${ }^{1}$, Jesús G. Pallarés², Ricardo Mora-Rodriguez ${ }^{1}$

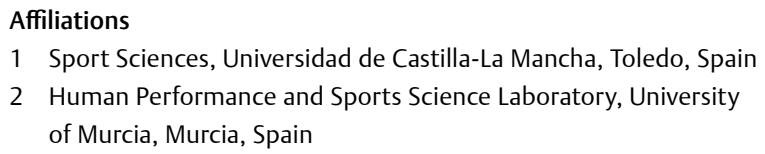

1 Sport Sciences, Universidad de Castilla-La Mancha, Toledo, Spain

2 Human Performance and Sports Science Laboratory, University of Murcia, Murcia, Spain

Key words

hypertension, vascular resistance, cardiac output, skin blood flow, insulin resistance syndrome $X$

accepted after revision 12.01.2017

\section{Bibliography}

DOI http://dx.doi.org/10.1055/s-0043-101911

Int J Sports Med 2017; 38: 1-8

(c) Georg Thieme Verlag KG Stuttgart · New York

ISSN 0172-4622

\section{Correspondence}

Dr. Ricardo Mora-Rodriguez

Sport Sciences

Universidad de Castilla-La Mancha

Avda. Carlos III s/n

45071, Toledo

Spain

Tel.: + 34/925/268 800 Ext.: 5510, Fax: + 34/925/268 846

Ricardo.Mora@uclm.es

\begin{abstract}
The purpose of this study was to compare the magnitude of post-exercise hypotension (PEH) after a bout of cycling exercise using high-intensity interval training (HIIT) in comparison to an isocaloric bout of traditional moderate-intensity continuous exercise (CE). After supine rest 14 obese $\left(31 \pm 1 \mathrm{~kg} \cdot \mathrm{m}^{-2}\right)$ middle-age $(57 \pm 2 \mathrm{y})$ metabolic syndrome patients ( $50 \%$ hypertensive) underwent a bout of HIIT and CE in a random order and then returned to supine recovery for another $45 \mathrm{~min}$. Exercise trials were isocaloric and compared to a no-exercise trial (CONT) of continuous supine rest for a total of $160 \mathrm{~min}$. Before and after exercise we assessed blood pressure (BP), heart rate (HR), cardiac output $(Q)$, systemic vascular resistance (SVR), intestinal temperature $\left(T_{I N T}\right)$, forearm skin blood flow $\left(\mathrm{S}_{\mathrm{K}} \mathrm{BF}\right)$ and percent dehydration. HIIT produced a larger reduction in systolic blood pressure than CE ( - $20 \pm 6$ vs. $-5 \pm 3 \mathrm{mmHg}$ in the hypertensive group and $-8 \pm 3$ vs. $-3 \pm 2 \mathrm{mmHg}$ in the normotensive group) and larger increases in resting $\mathrm{HR}(\mathrm{P}<0.005)$. Percent dehydration was larger after HIIT, and post-exercise $\mathrm{T}_{\text {INT }}$ and $\mathrm{S}_{\mathrm{K}} \mathrm{BF}$ increased only after HIIT $(\mathrm{P}<0.05)$. Our findings suggest that HIIT is a superior exercise method to $C E$ to transiently reduce blood pressure in MSyn subjects.
\end{abstract}

\section{Introduction}

Metabolic syndrome (MSyn) affects about $23 \%$ of the US adult population [5] and it is associated with poor blood pressure control in a large sample of European outpatients with hypertension [28]. Hypertension, one of the components of MSyn, increases the risk of developing stroke, coronary artery disease [48], heart failure, atrial fibrillation [4] and peripheral vascular diseases. The remaining MSyn components, increased waist circumference, dyslipidemia and impaired fasting glucose also increase the risk of cardiovascular diseases. Some of these factors interact among themselves to raise the risk of suffering cardiovascular diseases. For instance, abdominal obesity and excess weight raise the prevalence of hypertension [49] and thus the occurrence of adverse cardiovascular events [11]. Conversely, even moderate weight loss by caloric restriction results in substantial reductions in systolic and diastolic blood pressure (11 and $6 \mathrm{mmHg}$, respectively) in MSyn patients [7].

Aerobic exercise training, a non-pharmacological intervention, reduces resting blood pressure [46] even in people with resistant hypertension [12]. However, aerobic training does not lower blood pressure in the absence of body weight loss in obese patients [43] or MSyn patients $[2,50]$ despite a significant increase in cardiorespiratory fitness. In corroboration, a recent meta-analysis suggests that continuous moderate-intensity aerobic exercise training without concomitant weight loss does not improve arterial stiffness at least in obese adults [35]. In MSyn patients, aerobic training results in mild reductions in systolic blood pressure that are only noticeable when measured at the carotid artery [13].

One way to assess whether exercise lowers blood pressure in MSyn patients independently of the effects of reduced body weight is to study the blood pressure effect of a single bout of exercise (PEH). In healthy and essential hypertensive subjects, a bout of moderate aerobic exercise lowers resting blood pressure after exercise $[18,19,27,32]$. PEH reaches similar blood pressure reductions to those achieved by pharmacological means [29] and thus has the potential to reduce the risk of cardiovascular disease. However, a recent experiment cast doubt over the ability of a bout of exercise to lower blood pressure in MSyn patients. The study reveals that MSyn patients have a blunted PEH response to a bout of 
40 min of moderate-intensity aerobic exercise when compared to carefully matched counterparts [39].

High-intensity interval training (HIIT), a training mode originally used to improve athletic performance, has been quickly embraced in health fitness programs as less time-consuming and tedious than moderate-intensity continuous training while producing similar health benefits [15]. HIIT involves $30 \mathrm{~s}$ [33] to 4 min [22] periods of high-intensity exercise that elicit muscle accumulation of metabolites and hyperthermia, all of which have been regarded as mediators of vasodilation (i. e., histamine; [19]). However, some studies maintain that exercise intensity does not affect the magnitude or duration of PEH $[31,40]$. The few training studies using HIIT on MSyn patients suggest an effect on reducing resting blood pressure along with a concomitant reduction in body weight $[36,52]$, which makes it difficult to isolate the influence of exercise from weight loss on the reductions in blood pressure.

In this study, we sought to determine if a bout of cycling exercise using HIIT results in $\mathrm{PEH}$ in comparison to an isocaloric bout of traditional moderate-intensity continuous exercise (CE). The hypothesis we maintained is that intense exercise is required to lower blood pressure after exercise in the MSyn population. Identification of the hemodynamic factors that underlie PEH is key to direct strategies that potentiate these factors. We did a full assessment of physiological variables such as post-exercise oxygen consumption, heart rate, cardiac output, systemic vascular resistance, stroke volume, core and skin temperature, and blood flow to identify associations with $\mathrm{PEH}$ after each exercise bout.

\section{Methods}

\section{Participants}

14 middle-aged ( $57 \pm 8$ years) obese subjects ( $n=11$ males and $n=3$ females) with a body mass index of $31 \pm 4 \mathrm{~kg} \cdot \mathrm{m}^{-2}$ ( $\triangleright$ Table 1 ) and metabolic syndrome (MSyn; [1]) completed this study. Exclusion criteria included the use of medication known to affect heart rate response, (i. e., beta adrenergic receptor blockers or agonists and

- Table 1 Subject characteristics.

\begin{tabular}{|l|c|c|}
\hline & $\begin{array}{c}\text { Hypertensive } \\
(\mathbf{n}=\mathbf{7} ; \mathbf{5 0} \%)\end{array}$ & $\begin{array}{c}\text { Normotensive } \\
(\mathbf{n}=\mathbf{7} ; \mathbf{5 0} \%)\end{array}$ \\
\hline Age $(\mathrm{yrs})$ & $59 \pm 6$ & $55 \pm 9$ \\
\hline Weight $(\mathrm{kg})$ & $95.1 \pm 15.8$ & $79.9 \pm 9.1^{*}$ \\
\hline $\mathrm{BMI}\left(\mathrm{kg} \cdot \mathrm{m}^{-2}\right)$ & $33.0 \pm 4.8$ & $29.1 \pm 3.6$ \\
\hline $\begin{array}{l}\text { Waist circumference } \\
(\mathrm{cm})\end{array}$ & $112.6 \pm 10.7$ & $98.0 \pm 8.2^{*}$ \\
\hline Glucose $\left(\mathrm{mg} \cdot \mathrm{dl}^{-1}\right)$ & $107.6 \pm 14.2$ & $97.1 \pm 8.7$ \\
\hline $\begin{array}{l}\text { Triglycerides } \\
\left(\mathrm{mg} \cdot \mathrm{dl}^{-1}\right)\end{array}$ & $143.4 \pm 61.5$ & $116.9 \pm 56.8$ \\
\hline HDL-c $\left(\mathrm{mg} \cdot \mathrm{dl}^{-1}\right)$ & $49.3 \pm 8.8$ & $51.3 \pm 10.1$ \\
\hline HOMA IR & $3.2 \pm 1.8$ & $1.8 \pm 0.6$ \\
\hline $\begin{array}{l}\text { MSyn factors } \\
\text { (number) }\end{array}$ & $3.6 \pm 1.0$ & $3.0 \pm 0.6$ \\
\hline $\begin{array}{l}\text { Data presented as mean } \pm \text { SD for } 14 \text { metabolic syndrome pa- } \\
\text { tients. }{ }^{*} \text { Significant difference between groups. }{ }^{*} \mathrm{P}<0.05 \text { Hyperten- } \\
\text { sive vs. Normotensive }\end{array}$ \\
\hline
\end{tabular}

Proof copy for correction only. All forms of publication, calcium channel antagonists), untreated thyroid, cardiovascular or renal disease, or any condition associated with exercise intolerance. All subjects provided written, witnessed, informed consent of the protocol approved by the local Ethics Committee in accordance with the World Medical Association Declaration of Helsinki and as required by the journal [21].

\section{Preliminary testing}

Peak aerobic capacity $\left(\mathrm{VO}_{2 \text { PEAK }}\right)$ was assessed on an electronically-braked cycle ergometer (Ergoselect 200, Ergoline, Germany) during graded exercise testing (GXT) using indirect calorimetry (Quark b² , Cosmed, Italy) with 12-lead ECG monitoring (Quark T12, Cosmed, Italy). The highest heart rate value obtained during the test was considered HREAK.

\section{Experimental design}

Using a repeated-measures crossover randomized design, subjects completed 3 trials. One cycling trial consisted of a 10-min warmup followed by $5 \times 4$-min intervals at $90 \%$ of HR $\mathrm{H}_{\text {PEAK }}$ interspersed with 3 min of active recovery at $70 \% \mathrm{HR}_{\text {PEAK }}$ (HIIT trial). Another continuous exercise trial was conducted at $60 \% \mathrm{HR}_{\text {PEAK }}$ over $70 \pm 5 \mathrm{~min}$ (CE trial). In a third no-exercise control trial (CONT), subjects rested supine for $70 \mathrm{~min}$. Exercise duration for the HIIT and CE trials was calculated to match trials for energy expenditure ( $\sim 60$ kcals). During exercise, heart rate (HR) and blood pressure were monitored during the initial stages (10-25 min) and during the final stages (38-65 min) of exercise.

\section{Experimental protocol}

At least $72 \mathrm{~h}$ separated the trials and subjects were tested in the morning. $4 \mathrm{~h}$ before arriving at the laboratory, participants ingested a telemetric thermistor pill (CorTemp ${ }^{\mathrm{TM}}$, HQ, Inc., Palmetto, Florida, USA) for the measurement of intestinal temperature ( $\left.T_{\text {INT }}\right)$. $2 \mathrm{~h}$ before arrival to the laboratory subjects ingested a light breakfast of $500 \mathrm{kcal}$ and $65 \mathrm{~g}$ of carbohydrate. Upon arrival to the laboratory subjects voided and nude body weight was recorded (Toledo Hawk, Mettler, Columbus, $\mathrm{OH}, \mathrm{USA})$. Urine specific gravity $\left(\mathrm{U}_{\mathrm{SG}}\right)$ was measured to confirm euhydration $\left(U_{S G}<1.020\right.$; [45]). Then subjects were instrumented with an ECG-gated automated blood pressure sphygmomanometer (Tango ${ }^{\text {TM }}$ SunTech Medical, Inc., Morrisville, NC, USA) and a telemetric heart rate monitoring device (Accurex coded, Polar, Finland). Thereafter subjects lay on a stretcher and a laser Doppler flowmeter (Moor Lab, Moor Instruments, Devon, UK) was attached to the dorsal side of the forearm to measure skin blood flow $\left(S_{K} B F\right)$. Data was expressed as percent of maximal vasodilation elicited at the end of the trial by local heating to $42^{\circ} \mathrm{C}$. After 45 min of supine rest, blood pressure, metabolic and cardiovascular measurements were collected before and after exercise. At the end of exercise, subjects toweled dry and nude weight was measured again.

\section{Metabolic and cardiovascular measurements}

Before and after exercise, $\mathrm{O}_{2}$ consumption $\left(\mathrm{VO}_{2}\right)$ and $\mathrm{CO}_{2}$ production $\left(\mathrm{VCO}_{2}\right)$ were measured for 14 min using indirect calorimetry and energy expenditure was calculated [6]. Blood pressure (BP) was measured in triplicate on the left arm (Tango ${ }^{\text {TM }}$ SunTech Medical, Inc., Morrisville, NC, USA) and mean arterial pressure (MAP) calculated. HR was recorded every 5 min before, after and during exer- 
cise. Before and after exercise, cardiac output (Q) was measured in duplicate using the rebreathing technique (Innocor ${ }^{\mathrm{TM}}$, Innovision, Odense, Denmark). Stroke volume (SV) was calculated by dividing the $\mathrm{Q}$ between HR. Systemic vascular resistance (SVR) was calculated as MAP/Q.

\section{Thermoregulatory measurement}

Percent dehydration during exercise was calculated from changes in body weight. None of the participants urinated or ingested fluids during the trials and thus no corrections were needed. $T_{\text {INT }}$ and $S_{K} B F$ were collected continuously before and after exercise and data averaged every $5 \mathrm{~min}$. Cutaneous vascular resistance was calculated as $\mathrm{MAP} / \mathrm{S}_{\mathrm{K}} \mathrm{BF}$ and expressed in arbitrary units.

\section{Statistical analysis}

Normality was evaluated by the Shapiro-Wilk test. Data collected over time (PRE- and POST-exercise) in the 3 trials was analyzed using 2-way (treatment-by-time) repeated measures ANOVA. After a significant $F$ test, pairwise differences were identified using post hoc Tukey's HSD. Cohen's formula for effect size (ES; [9]) was used, and the results were based on the following criteria; $>0.70$ large effect; $0.30-0.69$ moderate effect; $\leq 0.30$ small effect. Minimal detectable change (MDC) was calculated as: MDC $=$ Z-score $(90 \%$ $\mathrm{Cl}) \times \mathrm{SEM} \times \sqrt{2}$ according to Costa et al. [10]. Data are presented as mean \pm SEM. Statistical significance level was set at $P \leq 0.05$.

\section{Results}

- Table 1 shows that when subjects were divided into hypertensive and normotensive groups, they were not different in age, BMI or in the number of MSyn factors. However, the weight and waist circumference were higher in the hypertensive subjects.

\section{Arterial pressure responses}

Before exercise (i.e., PRE), systolic blood pressure (SBP) was similar among trials for both the hypertensive and normotensive groups. After HIIT there was a reduction in SBP in the hypertensive group ( $134 \pm 7$ to $114 \pm 1 \mathrm{mmHg} ; P=0.023, E S=1.14 ; \boldsymbol{~}$ Fig. 1 a $)$ and in the normotensive group $(114 \pm 4$ to $107 \pm 3 \mathrm{mmHg} ; \mathrm{P}=0.045$, $E S=0.95$; $\triangleright$ Fig. 1c). However, CE and CONT did not affect SBP in either of the groups ( $\vee$ Fig. 1a, c). After exercise (POST) there was no difference among trials in SBP in the hypertensive group ( $\triangleright$ Fig. 1a), whereas in the normotensive group POST HIIT was lower than CE and CONT ( $P=0.008$ and $P=0.002$, respectively; - Fig. 1c).

Before exercise (PRE), diastolic blood pressure (DBP) was similar among trials in the hypertensive ( $\triangleright$ Fig. 1b) and normotensive ( $\triangleright$ Fig. 1d) groups. With exercise, DBP was reduced in the hypertensive group only in the HIIT trial $(81 \pm 3$ to $73 \pm 1 \mathrm{mmHg} ; \mathrm{P}=0.01$, $E S=0.90$; $\triangleright$ Fig. 1b). After exercise (POST), DBP in the hypertensive group was lower in HIIT than in the CONT trial $(P=0.03$; $>$ Fig. 1b), whereas there was no difference in DBP among trials POST in the normotensive group ( $\triangleright$ Fig. 1d).

\section{Minimal detectable change (MDC) analysis of blood pressure}

Systolic blood pressure MDC analysis resulted in $71 \%$ ( 10 out of 14 ) of the subjects reaching the systolic MDC (i. e., $6.72 \mathrm{mmHg}$ reduc- tion) following HIIT and $21 \%$ (3 out of 14) following CE. Diastolic blood pressure MDC analysis resulted in $57 \%$ (8 of 14) of the subjects reaching the diastolic MDC (i.e., $3.23 \mathrm{mmHg}$ reduction) following HIIT and $29 \%$ (4 of 14) following CE.

\section{Metabolic and cardiovascular responses}

There was no significant difference in cardiac output (Q) among trials PRE or POST. However, HIIT tended to increase Q from $5.7 \pm 0.2$ to $6.3 \pm 0.4 \mathrm{~L} \cdot \mathrm{min}^{-1}(P=0.23, E S=0.34$; $\triangleright$ Fig. $2 a)$. After exercise (POST), stroke volume (SV) was reduced in the HIIT trial (95.2 \pm 6.3 to $70.9 \pm 5.2 \mathrm{~mL} \mathrm{bt}^{-1} ; \mathrm{P}=0.001, \mathrm{ES}=1.18$ ) and maintained in the CE and CONT trials. As a result, SV was lower post-exercise in HIIT than in CONT $(P=0.002)$. From a similar pre-exercise value in all trials, HR increased after exercise in the HIIT and CE trials (62 \pm 2 to $89 \pm 2$ beat $\cdot \min ^{-1} ; P=0.001, E S=3.00$ and $60 \pm 3$ to $64 \pm 3$ beat $\cdot \min ^{-1} ; \mathrm{P}=0.02, \mathrm{ES}=0.69$; respectively) but not in the CONT ( $\triangleright$ Fig. 2b). The increases were larger in the HIIT trial, resulting in higher pos- exercise HR than in CE and CONT $(P<0.001)$.

There was no difference in systemic vascular resistance (SVR) among trials PRE-exercise, however post-exercise HIIT was lower than CE $\left(14 \pm 4\right.$ vs. $18 \pm 6 \mathrm{mmHg} \cdot\left(\mathrm{L} \cdot \mathrm{min}^{-1}\right)^{-1}, \mathrm{P}=0.01$; $>$ Fig. 3a). Cutaneous vascular resistance (CVR) before exercise (PRE) was increased in the CE trial. However, after exercise (POST), there was a reduction in CVR only in the HIIT trial (422 \pm 53 to $101 \pm 11$ arbitrary units; $P=0.001, E S=1.91$; Fig. $3 \mathbf{b})$. Although trials were isocaloric, HIIT resulted in larger EPOC than CE $(0.211 \pm 0.041$ vs. $\left.0.095 \pm 0.026 \mathrm{mLO}_{2} \cdot \mathrm{min}^{-1} ; \mathrm{P}<0.05\right)$.

\section{Thermoregulatory responses}

Percent dehydration measured from body weight losses was larger in the HIIT than in the CE trial $(0.85 \pm 0.07$ vs. $055 \pm 0.07 \%$, respectively; $\mathrm{P}=0.001 ; \mathrm{ES}=1.15) . \mathrm{S}_{\mathrm{K}} \mathrm{BF}$ was similar pre-exercise in all trials. SkBF only increased post-exercise in the HIIT trial being, above the rest of the trials ( $27 \pm 4$ to $92 \pm 7 \%, E S=2.78, P=0.001$; - Fig. 4a). Pre-exercise $T_{\text {INT }}$ was similar in all trials. However, post-exercise $\mathrm{T}_{\text {INT }}$ increased only after HIIT (36.8 \pm 0.2 to $37.7 \pm 0.2^{\circ} \mathrm{C} ; \mathrm{P}=0.001, \mathrm{ES}=2.56$ ), being larger than in the $\mathrm{CE}$ and CONT trials ( $\triangleright$ Fig. $\mathbf{4 b}$ ).

\section{Discussion}

We conducted this study to determine the magnitude of $\mathrm{PEH}$ after a single bout of high-intensity interval training (HIIT; [22]) in comparison to a isocaloric bout of traditional moderate-intensity continuous exercise (CE). HIIT has increased its popularity after reports showing training adaptations that promote health in young, healthy subjects [15]. In MSyn subjects, a 14-16 week HIIT program lowers blood pressure [36, 52] and improves endothelial function [52]. Concomitantly, those HIIT programs reduce body weight, which by itself is associated with lowering resting blood pressure [53]. By testing the effects of a single bout of HIIT on blood pressure, we avoided the concomitant effects of body weight loss. We found in a sample of MSyn patients that a bout of HIIT induces PEH in normotensive and hypertensive subjects ( $>$ Fig. 1). In the hypertensive subjects, the magnitude of $\mathrm{PEH}$ was similar to that reported in the literature (i. e., SBP $-20 \mathrm{mmHg}$ and DBP $-8 \mathrm{mmHg}$; [8]; > Fig. $\mathbf{1 a}, \mathbf{b})$. In the normotensive subjects, $\mathrm{PEH}$ was of a lesser magni- 

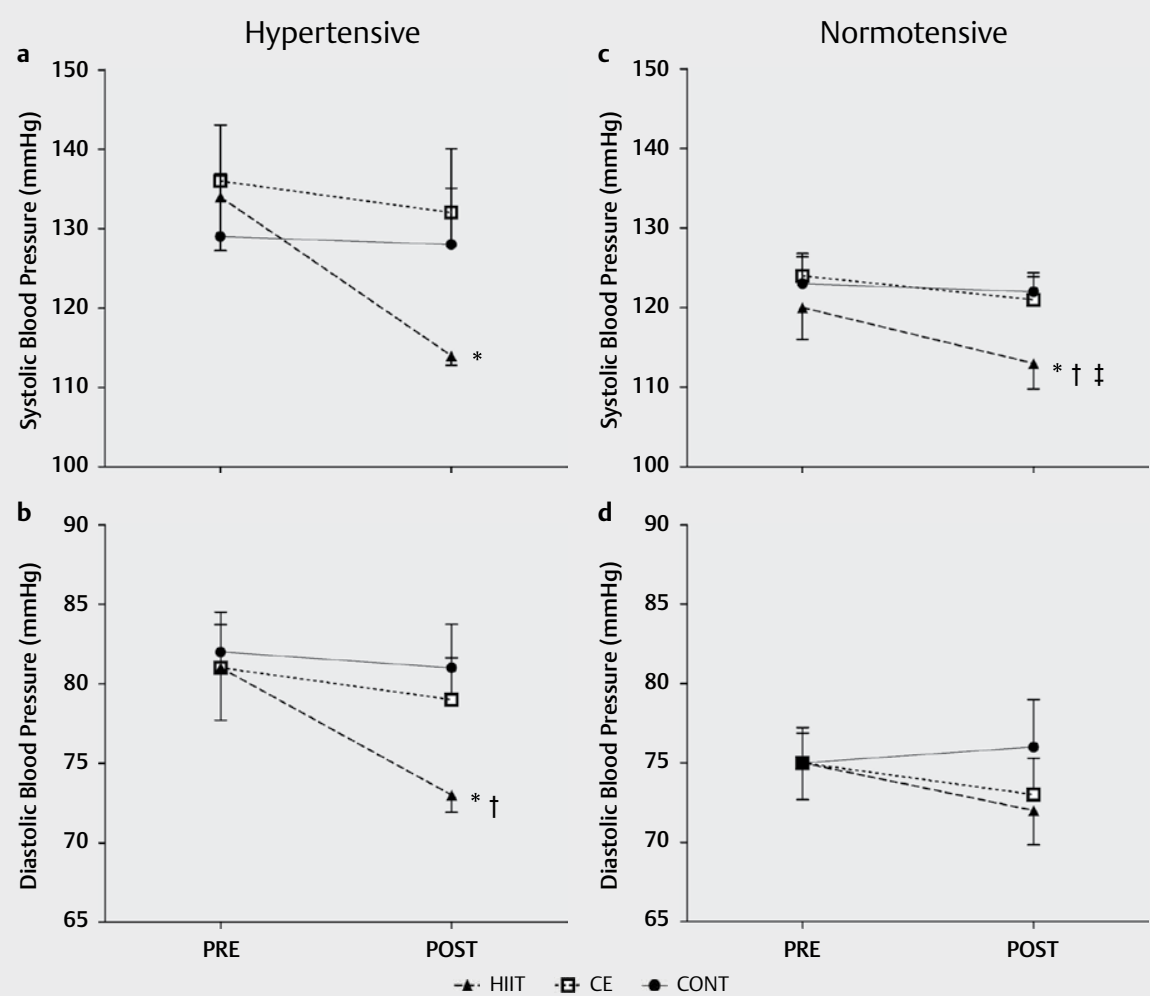

- Fig. 1 a Systolic and $\mathbf{b}$ diastolic blood pressure in the hypertensive group and $\mathbf{c}$ systolic and $\mathbf{d}$ diastolic blood pressure in the normotensive group, before (PRE) and after (POST) a bout of continuous exercise (CE) or high-intensity interval exercise (HIIT) equaled by total energy expenditure $(\sim 460 \mathrm{kcals})$ or a control no-exercise trial (CONT). Data are means \pm SEM for 14 middle-aged metabolic syndrome subjects.

${ }^{*}$ Significantly different from PRE-exercise for that trial $(P<0.05)$. $†$ Difference from CONT at that time point $(P<0.05)$.

$\ddagger$ Difference from $C E$ at that time point $(P<0.05)$.

tude than in the hypertensive subjects, as shown previously in other studies [8, 27]. PEH after HIIT was significantly larger than after CE in diastolic pressure for hypertensive subjects and in systolic pressure for the normotensive subjects. Our findings suggest that HIIT is a superior exercise method to acutely combat hypertension than an isocaloric bout of $\mathrm{CE}$, at least in the obese MSyn population.

We explored the hemodynamics behind the difference in $\mathrm{PEH}$ between HIIT and CE by measuring cardiac output (Q; - Fig. 2a) and calculating systemic vascular resistances (SVR). During exercise, $Q$ increases to satisfy the energy demands of the contracting muscle, and SVR declines in muscle and skin. In the return from exercise to rest, SVR remained at a lower level after the HIIT bout ( Fig. 3a). Apparently the systemic vasodilation after HIIT lowered central venous pressure, signaling low-pressure baroreceptors to increase Q [20] to prevent further lowering of blood pressure. Interestingly, our middle-aged deconditioned MSyn patients increased $Q$ by increasing heart rate (i. e., chronotropic effect; > Fig. 2b) rather than by increasing cardiac contractility and stroke volume, similar to what has been found in a younger, trained population [47].

An HIIT bout reduced cutaneous vascular resistance in parallel with SVR ( $\triangleright$ Fig. 3b). Thus, the incomplete recovery of resting vasoconstriction tone after the HIIT bout does not seem to be restricted to active skeletal muscle, but affects inactive vascular beds like the skin. It is tempting to conclude that the larger heat accumula- tion and cutaneous blood flow during HIIT ( $\vee$ Fig. 4a, b) are responsible for the PEH differences between HIIT and CE. However, experiments designed to examine the effects of skin circulation on $\mathrm{PEH}$ [54] using fluid replacement and exercise in a warm environment [30] reveal that the timing of reduced CVR and PEH differ. Specifically, $\mathrm{PEH}$ continues when CVR has returned to pre-exercise values [54]. Our experiment was conducted in a thermoneutral environment, but due to the intense bout of HIIT, subjects became dehydrated and increased their core temperature above the CE trial ( $>$ Fig. 4b). Our measurements started 45 min after completion of exercise, so it is possible that the larger PEH after HIIT was in some cases mediated by the lingering reductions in cutaneous vascular resistances at that time.

One of the main functions of the cardiovascular system is to deliver oxygen to all bodily tissues, and so we measured the excess post-exercise oxygen consumption (EPOC) after HIIT and CE. Although trials were isocaloric, HIIT resulted in larger EPOC than CE $\left(0.211 \pm 0.153\right.$ vs. $\left.0.095 \pm 0.102 \mathrm{mLO}_{2} \cdot \mathrm{min}^{-1} ; \mathrm{P}<0.05\right)$. Higher EPOC has been observed in diabetic patients after interval walking in comparison to continuous brisk walking [25]. The increased oxygen consumption/delivery requires greater cardiac output or greater oxygen extraction. It is possible that the increases in Q after HIIT were due not only to compensate for the incomplete recovery of SVR, but also to supply the extra oxygen demand of EPOC after 

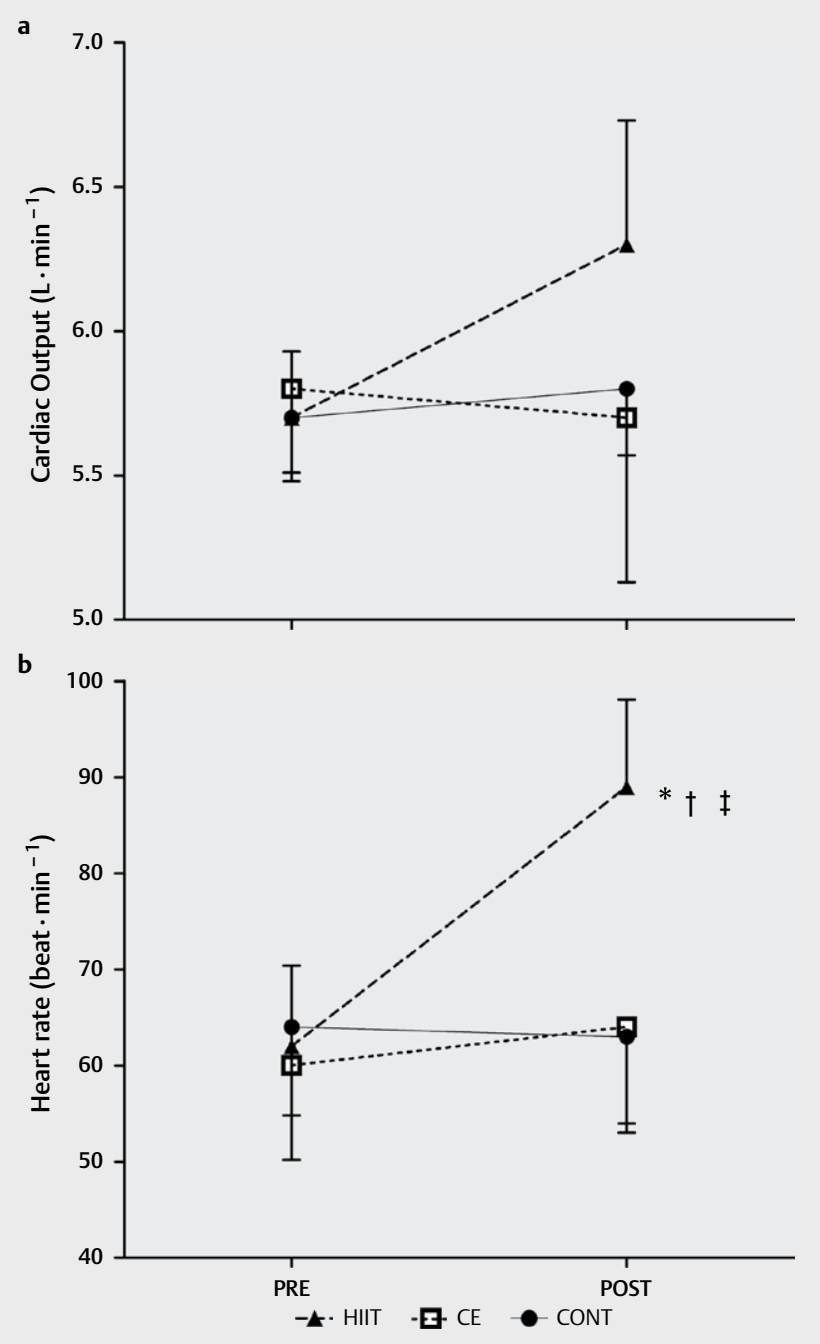

Fig. 2 a Cardiac output and $\mathbf{b}$ heart rate, before (PRE) and after (POST) a bout of continuous exercise (CE) or high-intensity interval exercise (HIIT) equaled by total energy expenditure ( $460 \mathrm{kcals})$ or a control no-exercise trial (CONT). Data are means \pm SEM for 14 middle-aged metabolic syndrome subjects. ${ }^{*}$ Significantly different from PRE-exercise for that trial $(P<0.05)$. $†$ Difference from CONT at that time point $(P<0.05)$. $\ddagger$ Difference from $C E$ at that time point $(\mathrm{P}<0.05)$.

the HIIT bout. To our knowledge, ours is the first study to integrate EPOC as a possible factor in the PEH response.

It is well documented that PEH occurs upon prolonged moderate-intensity continuous aerobic exercise [51]. However, there is no a clear consensus on the type, intensity and duration of exercise that elicits the larger and more sustained $\mathrm{PEH}$ response. Initial reports in hypertensive older humans maintain that the magnitude of PEH is larger the higher the exercise intensity [16]. However, in middle-aged hypertensive [40] or normotensive [31] adults, PEH was not different after mild- or moderate-intensity continuous cycling. Those studies led to early recommendations of light to moderately intense exercise to combat hypertension [41], which continues to be the prevailing recommendation. However, this view has started to change recently upon the appearance of studies showing that vigorous exercise results in larger PEH than moder- a

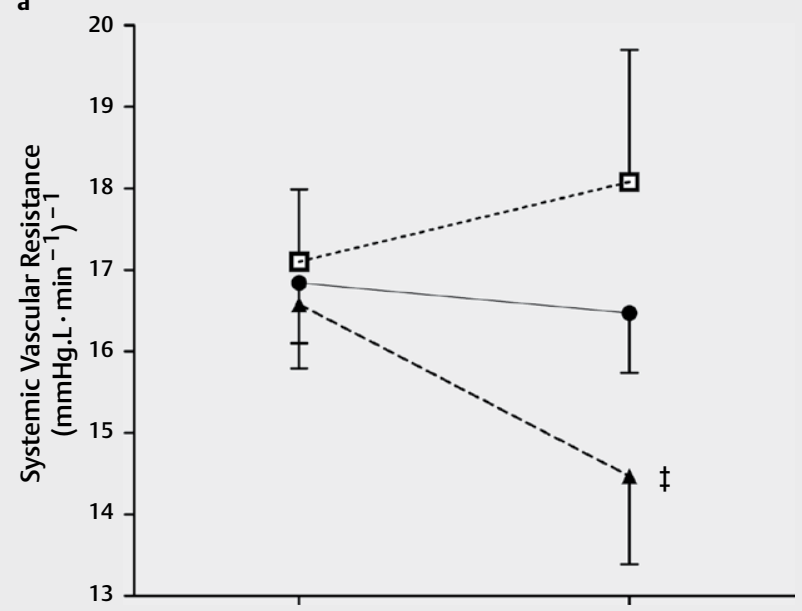

b

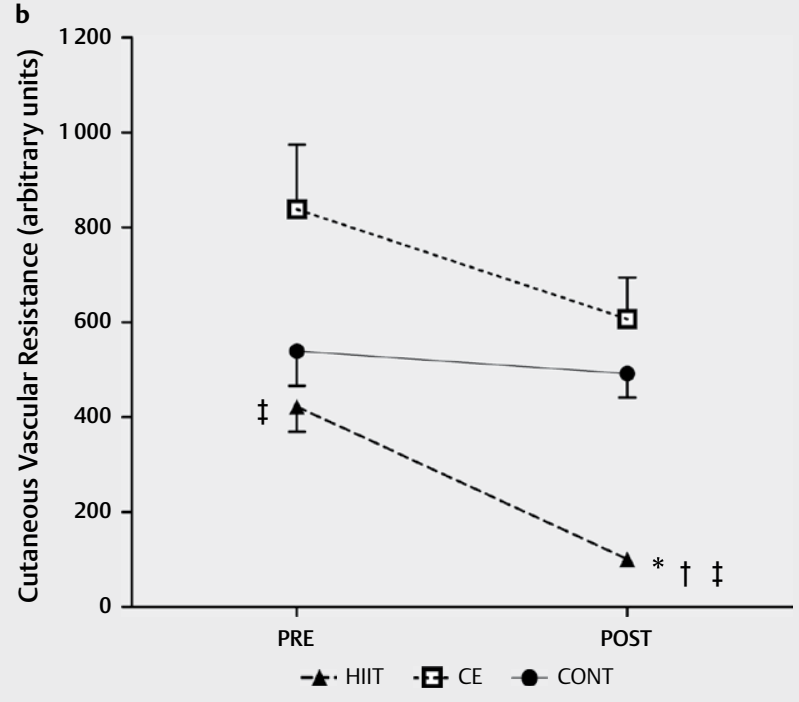

- Fig. 3 a Systemic vascular resistance and $\mathbf{b}$ cutaneous vascular resistance, before (PRE) and after (POST) a bout of continuous exercise (CE) or high-intensity interval exercise (HIIT) equaled by total energy expenditure ( $460 \mathrm{kcals})$ or a control no-exercise trial (CONT). Data are means \pm SEM for 14 middle-aged metabolic syndrome subjects. * Significantly different from PRE-exercise for that trial $(P<0.05)$. $\dagger$ Difference from CONT at that time point $(P<0.05)$. $\ddagger$ Difference from $C E$ at that time point $(P<0.05)$. 

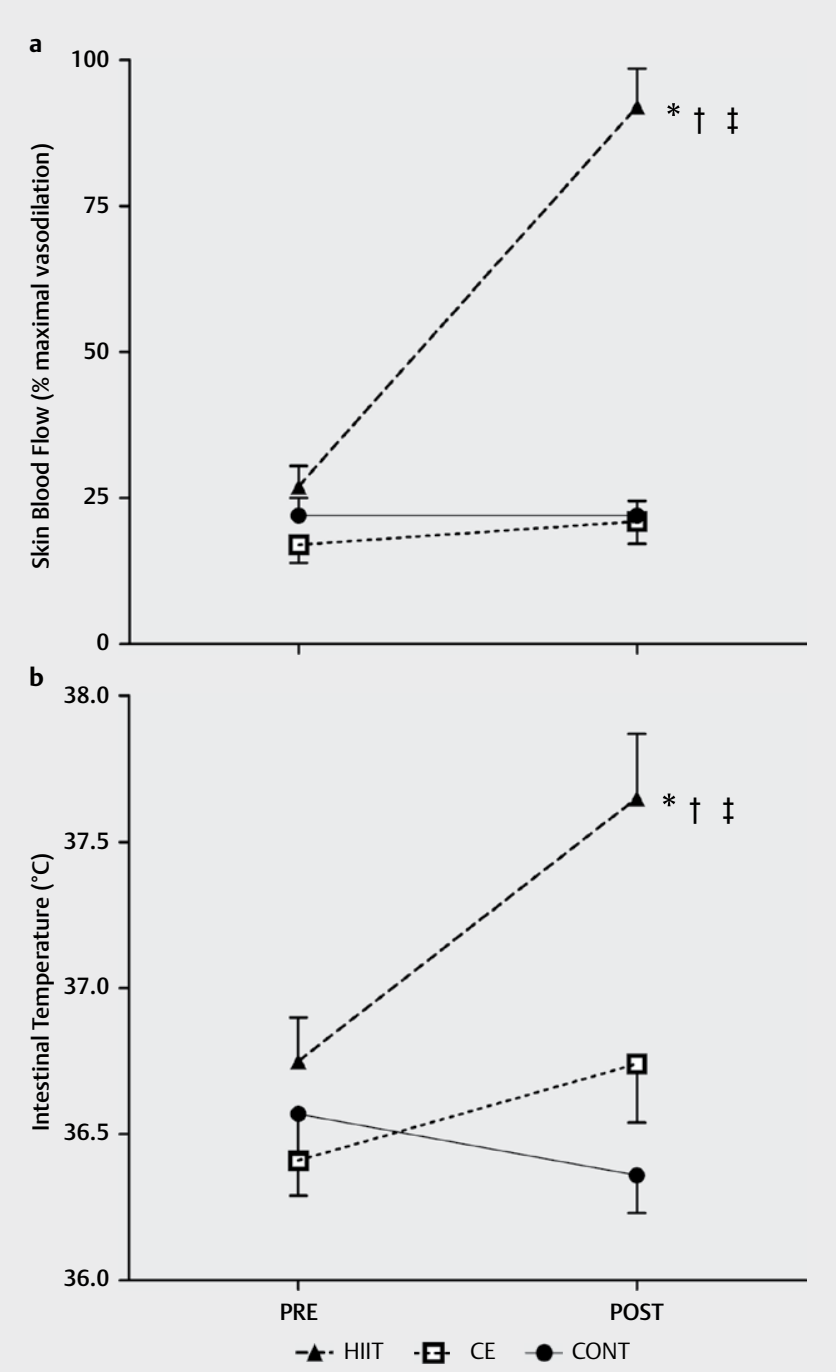

- Fig. 4 a Skin blood flow and b intestinal temperature, before (PRE) and after (POST) a bout of continuous exercise (CE) or high-intensity interval exercise (HIIT) equaled by total energy expenditure ( $460 \mathrm{kcals})$ or a control no-exercise trial (CONT). Data are means \pm SD for 14 middle-aged metabolic syndrome subjects.

* Significantly different from PRE-exercise for that trial $(P<0.05)$. $\dagger$ Difference from CONT at that time point $(P<0.05)$. $\ddagger$ Difference from $C E$ at that time point $(P<0.05)$.

ported that 70 min of moderate-intensity exercise (i.e., CE trial) only reduces diastolic blood pressure in our MSyn participants. However, the blunted $\mathrm{PEH}$ response after $\mathrm{CE}$ was not found after the isocaloric HIIT bout ( $\triangleright$ Fig. 1). The factors behind the different PEH response after HIIT vs. CE are not clear. However, as advanced by Pescatello and colleagues, the cardiovascular insulin actions may be involved in $\mathrm{PEH}$. We have recently found that shorter-interval exercise (i.e., 4 Wingate tests) improves insulin sensitivity 30 min after exercise [37] whereas isocaloric continuous moderate-intensity exercise does not. Thus, it is possible that the vasodilating effects of insulin are facilitated by HIIT but not by lower exercise intensity (i.e., CE).

It is not clear if total energy expended during exercise influences the magnitude of $\mathrm{PEH}[23,38]$. Our bouts of exercise were iso- caloric and however PEH was markedly different after HIIT and CE. Thus, our data suggest that something about HIIT caused the more favorable PEH response. HIIT is not only different from CE in exercise intensity but also in the exercise pattern that produces sequential changes in blood pressure and thus shear forces in the vasculature during exercise. It has been proposed that those shear forces are the main stimulus for the production and release of nitric oxide (NO) by the endothelium, which is an strong vasodilator [24]. It has been found that NO plasma concentration is higher during intense exercise in association with higher PEH in hypertensive women [44]. However, NO blockade experiments question how much of the PEH response could be attributed to NO [20].

We performed a minimal detectable change (MDC) analysis of the blood pressure response because it has been reported that $\mathrm{PEH}$ may be a heterogeneous physiological phenomenon with responders and non-responders, rendering it impossible to appreciate the potential effects of different exercise methods (i. e., continuous vs. interval [10]) on PEH. However, 10 out of 14 subjects (71\%) responded to HIIT with detectable reductions in systolic blood pressure, whereas only 3 out of 14 (21\%) responded with reductions after CE. Data for diastolic pressure followed the same pattern. These results coincide with our ANOVA analysis, confirming that the effects of exercise mode are stronger than the possible biological variability in the response to different exercise methods. Costa et al. [10] tested young, healthy normotensive males, whereas our participants were middle-aged, hypertensive (50\% of the sample) and suffered from metabolic syndrome (all of them). Undoubtedly, the scope for blood pressure improvement was larger in our sample, which could explain the more homogeneous blood pressure responses, unveiling the statistical differences between exercise methods (i. e., continuous vs. interval).

There are some limitations to our study. We tested PEH 45 min after exercise because it has been reported that the $\mathrm{PEH}$ nadir occurs around that time. However, we did not follow the blood response to exercise during the following 12 waking hours, and thus the clinical potential to manage hypertension with HIIT bouts is uncertain. Our results pertain to one bout of exercise and suggest that interval intense exercise is superior to elicit PEH. However, there are some reports stating that high-intensity training over months has less final effect on reducing blood pressure than milder but longer bouts of training [17, 34].

In summary, long-term training treatments in hypertensive people may not be justified without first demonstrating an acute response. Thus, the study of the effect of a HIIT and CE bout on post-exercise hypotension (PEH) is important to deliver efficient exercise advice to hypertensive individuals. Our data suggest that exercise intensity and exercise method (interval vs. continuous) are determinant factors of $\mathrm{PEH}$, whereas total energy expenditure during exercise has a marginal effect on $\mathrm{PEH}$. The underlying mechanisms that trigger this differential PEH response are unclear but could be related to the higher vascular shear forces during exercise, the higher excess post-exercise oxygen consumption, and/or the greater heat accumulated after HIIT in comparison with CE. From a practical point of view, our findings suggest that HIIT is a superior exercise method to acutely combat hypertension than an isocaloric bout of CE, at least in the obese metabolic syndrome population. 


\section{Acknowledgements}

This work was partially funded by a grant from the Spanish Ministry of Economy and Competivity (DEP-2014-52930-R).

\section{Conflict of interest}

There is no conflict of interest.

\section{References}

[1] Alberti KG, Eckel RH, Grundy SM, Zimmet PZ, Cleeman JI, Donato KA, Fruchart JC, James WP, Loria CM, Smith SC Jr., International Diabetes Federation Task Force on Epidemiology and Prevention; National Heart, Lung, and Blood Institute; American Heart Association; World Heart Federation; International Atherosclerosis Society; International Association for the Study of Obesity. Harmonizing the metabolic syndrome: a joint interim statement of the International Diabetes Federation Task Force on Epidemiology and Prevention; National Heart, Lung, and Blood Institute; American Heart Association; World Heart Federation; International Atherosclerosis Society; and International Association for the Study of Obesity. Circulation 2009; 120: $1640-1645$

[2] Anderssen SA, Carroll S, Urdal P, Holme I. Combined diet and exercise intervention reverses the metabolic syndrome in middle-aged males: results from the Oslo Diet and Exercise Study. Scand J Med Sci Sports 2007; 17: 687-695

[3] Angadi SS, Bhammar DM, Gaesser GA. Postexercise hypotension after continuous, aerobic interval, and sprint interval exercise. J Strength Cond Res 2015; 29: 2888-2893

[4] Angeli F, Reboldi G, Verdecchia P. Hypertension, inflammation and atrial fibrillation. J Hypertens 2014; 32: 480-483

[5] Beltran-Sanchez H, Harhay MO, Harhay MM, McElligott S. Prevalence and trends of metabolic syndrome in the adult U.S. population, 1999-2010. J Am Coll Cardiol 2013; 62: 697-703

[6] Brouwer E. On simple formulae for calculating the heat expenditure and the quantities of carbohydrate and fat oxidized in metabolism of men and animals, from gaseous exchange (Oxygen intake and carbonic acid output) and urine-N. Acta Physiol Pharmacol Neerl 1957; 6: 795-802

[7] Case CC, Jones PH, Nelson K, O'Brian Smith E, Ballantyne CM. Impact of weight loss on the metabolic syndrome. Diabetes Obes Metab 2002; 4: 407-414

[8] Cleroux J, Kouame N, Nadeau A, Lacourciere Y. Forearm hemodynamics during recovery from exercise in hypertensive and normotensive subjects. J Hypertens Suppl 1991; 9: S124-S125

[9] Cohen J. Statistical Power Analysis for the Behavioral Sciences. $2^{\text {nd }}$ ed. Hillsdale (NJ): Lawrence Erlbaum Associates; 1988

[10] Costa EC, Dantas TC, de Farias Junior LF, Frazao DT, Prestes J, Moreira SR, Ritti-Dias RM, Tibana RA, Duhamel TA. Inter- and intra-individual analysis of post-exercise hypotension following a single bout of high-intensity interval exercise and continuous exercise: a pilot study. Int J Sports Med 2016, doi:10.1055/s-0042-112029

[11] DeVallance E, Fournier SB, Donley DA, Bonner DE, Lee K, Frisbee JC, Chantler PD. Is obesity predictive of cardiovascular dysfunction independent of cardiovascular risk factors? Int J Obes (Lond) 2015; 39 : 244-253

[12] Dimeo F, Pagonas N, Seibert F, Arndt R, Zidek W, Westhoff TH. Aerobic exercise reduces blood pressure in resistant hypertension. Hypertension 2012; 60: 653-658
[13] Donley DA, Fournier SB, Reger BL, DeVallance E, Bonner DE, Olfert IM, Frisbee JC, Chantler PD. Aerobic exercise training reduces arterial stiffness in metabolic syndrome. J Appl Physiol 2014; 116: 1396-1404

[14] Eicher JD, Maresh CM, Tsongalis G], Thompson PD, Pescatello LS. The additive blood pressure lowering effects of exercise intensity on post-exercise hypotension. Am Heart J 2010; 160: 513-520

[15] Gibala MJ, Little JP, Macdonald MJ, Hawley JA. Physiological adaptations to low-volume, high-intensity interval training in health and disease. J Physiol 2012; 590: 1077-1084

[16] Hagberg JM, Montain SJ, Martin WH $3^{\text {rd }}$. Blood pressure and hemodynamic responses after exercise in older hypertensives. J Appl Physiol 1987; 63: 270-276

[17] Hagberg JM, Montain SJ, Martin WH $3^{\text {rd }}$, Ehsani AA. Effect of exercise training in 60- to 69-year-old persons with essential hypertension. Am J Cardiol 1989; 64: 348-353

[18] Halliwill JR. Mechanisms and clinical implications of post-exercise hypotension in humans. Exerc Sport Sci Rev 2001; 29: 65-70

[19] Halliwill JR, Buck TM, Lacewell AN, Romero SA. Postexercise hypotension and sustained postexercise vasodilatation: what happens after we exercise? Exp Physiol 2013; 98: 7-18

[20] Halliwill JR, Minson CT, Joyner MJ. Effect of systemic nitric oxide synthase inhibition on postexercise hypotension in humans. J Appl Physiol 2000; 89: 1830-1836

[21] Harriss D], Atkinson G. Ethical standards in sport and exercise science research: 2016 update. Int J Sports Med 2015; 36: 1121-1124

[22] Helgerud J, Hoydal K, Wang E, Karlsen T, Berg P, Bjerkaas M, Simonsen T, Helgesen C, Hjorth N, Bach R, Hoff J. Aerobic high-intensity intervals improve VO2max more than moderate training. Med Sci Sports Exerc 2007; 39: 665-671

[23] Jones H, George K, Edwards B, Atkinson G. Is the magnitude of acute post-exercise hypotension mediated by exercise intensity or total work done? Eur J Appl Physiol 2007; 102: 33-40

[24] Jungersten L, Ambring A, Wall B, Wennmalm A. Both physical fitness and acute exercise regulate nitric oxide formation in healthy humans. J Appl Physiol 1997; 82: 760-764

[25] Karstoft K, Wallis GA, Pedersen BK, Solomon TP. The effects of interval- vs. continuous exercise on excess post-exercise oxygen consumption and substrate oxidation rates in subjects with type 2 diabetes. Metabolism 2016; 65: 1316-1325

[26] Keese F, Farinatti P, Pescatello L, Cunha FA, Monteiro WD. Aerobic exercise intensity influences hypotension following concurrent exercise sessions. Int J Sports Med 2012; 33: 148-153

[27] Kenney M], Seals DR. Postexercise hypotension. Key features, mechanisms, and clinical significance. Hypertension 1993; 22: 653-664

[28] Kjeldsen SE, Naditch-Brule L, Perlini S, Zidek W, Farsang C. Increased prevalence of metabolic syndrome in uncontrolled hypertension across Europe: the Global Cardiometabolic Risk Profile in Patients with hypertension disease survey. J Hypertens 2008; 26: 2064-2070

[29] Lewington S, Clarke R, Qizilbash N, Peto R, Collins R, Prospective Studies C. Age-specific relevance of usual blood pressure to vascular mortality: a meta-analysis of individual data for one million adults in 61 prospective studies. Lancet 2002; 360: 1903-1913

[30] Lynn BM, Minson CT, Halliwill JR. Fluid replacement and heat stress during exercise alter post-exercise cardiac haemodynamics in endurance exercise-trained men. J Physiol 2009; 587: 3605-3617

[31] MacDonald J, MacDougall J, Hogben C. The effects of exercise intensity on post exercise hypotension. J Hum Hypertens 1999; 13: 527-531

[32] MacDonald JR. Potential causes, mechanisms, and implications of post exercise hypotension. J Hum Hypertens 2002; 16: 225-236 
[33] MacDougall JD, Hicks AL, MacDonald JR, McKelvie RS, Green H], Smith KM. Muscle performance and enzymatic adaptations to sprint interval training. J Appl Physiol 1998; 84: 2138-2142

[34] Matsusaki M, Ikeda M, Tashiro E, Koga M, Miura S, Ideishi M, Tanaka H, Shindo M, Arakawa K. Influence of workload on the antihypertensive effect of exercise. Clin Exp Pharmacol Physiol 1992; 19: 471-479

[35] Montero D, Roberts CK, Vinet A. Effect of aerobic exercise training on arterial stiffness in obese populations : a systematic review and meta-analysis. Sports Med 2014; 44: 833-843

[36] Mora-Rodriguez R, Ortega JF, Hamouti N, Fernandez-Elias VE, Canete Garcia-Prieto J, Guadalupe-Grau A, Saborido A, Martin-Garcia M, Guio de Prada V, Ara I, Martinez-Vizcaino V. Time-course effects of aerobic interval training and detraining in patients with metabolic syndrome. Nutr Metab Cardiovasc Dis 2014; 24: 792-798

[37] Ortega JF, Fernandez-Elias VE, Hamouti N, Pallares JG, Mora-Rodriguez R. Higher insulin-sensitizing response after sprint interval compared to continuous exercise. Int J Sports Med 2015; 36: 209-214

[38] Padilla J, Wallace JP, Park S. Accumulation of physical activity reduces blood pressure in pre- and hypertension. Med Sci Sports Exerc 2005; 37: 1264-1275

[39] Pescatello LS, Blanchard BE, Van Heest JL, Maresh CM, Gordish-Dressman $\mathrm{H}$, Thompson PD. The metabolic syndrome and the immediate antihypertensive effects of aerobic exercise: a randomized control design. BMC Cardiovasc Disord 2008; 8: 12

[40] Pescatello LS, Fargo AE, Leach CN Jr., Scherzer HH. Short-term effect of dynamic exercise on arterial blood pressure. Circulation 1991; 83: 1557-1561

[41] Pescatello LS, Franklin BA, Fagard R, Farquhar WB, Kelley GA, Ray CA. American College of Sports Medicine. American College of Sports Medicine position stand. Exercise and hypertension. Med Sci Sports Exerc 2004; 36: 533-553

[42] Piepoli M, Isea JE, Pannarale G, Adamopoulos S, Sleight P, Coats A]. Load dependence of changes in forearm and peripheral vascular resistance after acute leg exercise in man. J Physiol 1994; 478 (Pt 2): 357-362

[43] Ross R, Dagnone D, Jones PJ, Smith H, Paddags A, Hudson R, Janssen I. Reduction in obesity and related comorbid conditions after diet-induced weight loss or exercise-induced weight loss in men. A randomized, controlled trial. Ann Intern Med 2000; 133: 92-103
[44] Santana HA, Moreira SR, Asano RY, Sales MM, Cordova C, Campbell CS, Espindola FS, Sposito AC, Nobrega OT, Simoes HG. Exercise intensity modulates nitric oxide and blood pressure responses in hypertensive older women. Aging Clin Exp Res 2013; 25: 43-48

[45] Sawka MN, Burke LM, Eichner ER, Maughan RJ, Montain S], Stachenfeld NS. American College of Sports Medicine position stand. Exercise and fluid replacement. Med Sci Sports Exerc 2007; 39: 377-390

[46] Seals DR, Hagberg JM. The effect of exercise training on human hypertension: a review. Med Sci Sports Exerc 1984; 16: 207-215

[47] Senitko AN, Charkoudian N, Halliwill JR. Influence of endurance exercise training status and gender on postexercise hypotension. J Appl Physiol 2002; 92: 2368-2374

[48] Shen L, Ma H, Xiang MX, Wang JA. Meta-analysis of cohort studies of baseline prehypertension and risk of coronary heart disease. Am J Cardiol 2013; 112: 266-271

[49] Stamler R, Stamler ], Riedlinger WF, Algera G, Roberts RH. Weight and blood pressure. Findings in hypertension screening of 1 million Americans. JAMA 1978; 240: 1607-1610

[50] Stuart CA, South MA, Lee ML, McCurry MP, Howell ME, Ramsey MW Stone $\mathrm{MH}$. Insulin responsiveness in metabolic syndrome after eight weeks of cycle training. Med Sci Sports Exerc 2013; 45: 2021-2029

[51] Thompson PD, Crouse SF, Goodpaster B, Kelley D, Moyna N, Pescatello L. The acute versus the chronic response to exercise. Med Sci Sports Exerc 2001; 33: S438-S445 discussion S452-S433

[52] Tjonna AE, Lee S], Rognmo O, Stolen TO, Bye A, Haram PM, Loennechen JP, Al-Share QY, Skogvoll E, Slordahl SA, Kemi OJ, Najjar SM, Wisloff $U$. Aerobic interval training versus continuous moderate exercise as a treatment for the metabolic syndrome: a pilot study. Circulation 2008; 118: 346-354

[53] Tyson CC, Appel L], Vollmer WM, Jerome G], Brantley PJ, Hollis JF, Stevens VJ, Ard JD, Patel UD, Svetkey LP. Impact of 5-year weight change on blood pressure: results from the Weight Loss Maintenance trial. J Clin Hypertens (Greenwich) 2013; 15: 458-464

[54] Wilkins BW, Minson CT, Halliwill JR. Regional hemodynamics during postexercise hypotension. II. Cutaneous circulation. J Appl Physiol 2004; 97: 2071-2076 